\title{
PERDAS DE SOLO E CARACTERIZAÇÃO FÍSICA E MICROMORFOLÓGICA DE CROSTAS FORMADAS EM SOLOS SOB CHUVA SIMULADA ${ }^{1}$
}

\author{
VIVIANE DOS S. BRANDÃO ${ }^{2}$, DEMÉTRIUS D. DA SILVA ${ }^{3}$, HUGO A. RUIZ ${ }^{4}$, \\ FERNANDO F. PRUSKI ${ }^{5}$, CARLOS E. G. R. SCHAEFER ${ }^{6}$, MAURO A. MARTINEZ ${ }^{3}$, \\ EDUARDO O. SILVA ${ }^{7}$
}

\begin{abstract}
RESUMO: Devido aos prejuízos provocados pela erosão sobre sistemas agrários e urbanos, foi desenvolvido este artigo para que se possa estabelecer relação entre a erosão e o selamento formado pelo impacto das gotas de chuva. Para avaliar as perdas de solo e as características físicas e micromorfólogicas das crostas desenvolvidas pelo impacto das gotas de água, foi realizado experimento, utilizando simulador de chuvas, num esquema fatorial $5 \times 6$, sendo cinco solos (Argissolo Vermelho, Argissolo Vermelho-Amarelo, Latossolo Vermelho-Amarelo, Neossolo Flúvico e Neossolo Quartzarênico) e seis energias cinéticas de chuva simulada $(0 ; 525 ; 1.051$; $2.102 ; 3.153$ e $4.204 \mathrm{~J} \mathrm{~m}^{-2}$ ), com três repetições. As perdas de solo foram determinadas por amostragem do volume total de escoamento superficial e as características físicas e micromorfológicas da crosta, tais como distribuição e continuidade dos poros, por meio de técnicas de micromorfometria. Em todos os solos avaliados, as perdas de solo aumentaram progressivamente com a energia cinética aplicada, sendo essas perdas menos acentuadas nos solos com textura grossa ou argilosos com estrutura microgranular. Foi evidenciada a formação de crostas estruturais e erosionais, e suas características apresentaram variação temporal dependente da energia cinética da chuva e da tensão cisalhante do escoamento superficial.
\end{abstract}

PALAVRAS-CHAVE: selamento, escoamento superficial, energia cinética da chuva.

\section{SOIL LOSSES AND PHYSICAL AND MICROMORPHOLOGICAL CHARACTERIZATION OF FORMED CRUSTS IN SOILS UNDER SIMULATED RAINFALL}

\begin{abstract}
Due to the damage caused by erosions in land and urban systems, this article has been developed to establish the relation between soil losses and superficial sealing formed by rain drop impact. In order to evaluate soil losses and physical and micromorphological characteristics of soil crusts developed by water drop impact, an experiment was carried out using a rainfall simulator in a factorial scheme of 5 x 6. Five soils (Red Ultisol, Red-Yellow Ultisol, Red-Yellow Oxisol, Fluvic Entisol and Arenic Entisol) and six rainfall kinetic energy $(0 ; 525 ; 1,051 ; 2,102$; 3,153 and 4,204 $\mathrm{J} \mathrm{m}^{-2}$ ) with three repetitions were used. Soil losses were determined by the total runoff volume samples and the physical and micromorphological characteristics of the crust, such as pores distribution and continuity, using micromorphometrics techniques. In all evaluated soils there was a progressive increase of soil losses with the kinetic energy applied. These losses were less accentuated in sandy or loamy texture soils with microgranular structure. Crust characteristics presented temporal variation, which were dependent of rainfall kinetic energy and runoff shear stress that induce structural and erosional crusts formation.
\end{abstract}

KEYWORDS: superficial sealing, runoff, rainfall kinetic energy.

\footnotetext{
${ }^{1}$ Extraído da tese de doutorado do primeiro autor. Projeto financiado pela FAPEMIG.

${ }^{2}$ Eng $^{\mathbf{a}}$ Agrônoma, D.S., Especialista em Recursos Hídricos, Agência Nacional de Águas, Brasília - DF, Fone: (0XX61) 2109-5253; vbrandao@ana.gov.br

${ }^{3}$ Eng $^{\mathrm{o}}$ Agrônomo, Prof. Adjunto, Departamento de Engenharia Agrícola, UFV, Viçosa - MG, Bolsista do CNPq.

${ }^{4}$ Bioquímico, Prof. Titular, Departamento de Solos, UFV, Viçosa, MG. Bolsista do CNPq.

${ }^{5}$ Eng $^{\mathrm{o}}$ Agrícola, Prof. Titular, Departamento de Engenharia Agrícola, UFV, Viçosa - MG, Bolsista do CNPq.

${ }^{6}$ Eng $^{\mathrm{o}}$ Agrônomo, Prof. Adjunto, Departamento de Solos, UFV, Viçosa - MG, Bolsista do CNPq.

${ }^{7}$ Graduando em Engenharia Agrícola, Departamento de Engenharia Agrícola, UFV, Viçosa - MG, Bolsista da FAPEMIG.

Recebido pelo Conselho Editorial em: 28-9-2004
}

Aprovado pelo Conselho Editorial em: 4-12-2006 


\section{INTRODUÇÃO}

A formação de crosta decorrente do impacto das gotas da chuva é um dos fatores que pode reduzir acentuadamente a infiltração e, conseqüentemente, aumentar o escoamento superficial, contribuindo para a erosão do solo.

O selamento é resultante de processos dinâmicos complexos, nos quais as partículas do solo são rearranjadas e consolidadas em uma estrutura superficial coesa, cuja espessura pode variar de $0,1 \mathrm{~mm}$ até valores superiores a $50 \mathrm{~mm}$ (VALENTIN \& BRESSON, 1992). Embora a espessura da camada selada possa ser relativamente pequena, seu efeito sobre as propriedades físicas da camada superficial do solo, como a redução da macroporosidade, proporciona expressiva diminuição da infiltração (SILVA \& KATO, 1997; McINTYRE, 1958).

Segundo VALENTIN \& BRESSON (1992), os três principais tipos de crostas são: estruturais, deposicionais e erosionais. As crostas estruturais são formadas pelo rearranjo in situ das partículas e microagregados, resultantes do distúrbio estrutural provocado pelo impacto das gotas de chuva. As crostas deposicionais estão relacionadas ao processo de sedimentação das partículas em microdepressões, cuja orientação das partículas grossas e finas depende das condições hidrodinâmicas do escoamento superficial (VALENTIN \& BRESSON, 1992). As crostas erosionais compreendem uma camada superficial rígida e lisa, constituída por partículas finas e resultam da erosão das crostas estruturais (CHEN et al., 1980).

Muitos trabalhos têm ressaltado a importância da manutenção de cobertura vegetal para a conservação do solo (McINTYRE, 1958; BERTOL et al., 1989; FARIA et al., 1998). A cobertura vegetal aumenta a macroporosidade da camada superficial e protege os agregados do impacto direto das gotas de chuva, sendo, dessa forma, capaz de manter altas taxas de infiltração.

A textura e a estrutura são as características que mais influenciam na movimentação da água no solo. Aqueles de textura grossa (arenosos) possuem maior quantidade de macroporos do que os de textura fina (argilosos) e, conseqüentemente, apresentam, quando saturados, maiores valores de condutividade hidráulica e taxa de infiltração.

Por outro lado, solos argilosos bem estruturados (estrutura estável) podem apresentar taxas de infiltração tão altas quanto as dos solos arenosos, e apresentam, seguramente, taxas de infiltração maiores do que os solos argilosos com estrutura instável.

A estabilidade de agregados é determinada por agentes cimentantes, tais como a matéria orgânica e os óxidos de Fe (hematita e goethita) e Al (gibsita). Os óxidos de Fe são os minerais secundários, produto final do intemperismo avançado dos solos. Dessa forma, quanto maior a presença desses compostos no solo, tanto mais estável será a sua estrutura. Da mesma forma, os solos ricos em argilas do tipo 2:1 tendem a formar crostas mais duras do que aqueles ricos em argilas do tipo 1:1, tal como a caulinita (SHAINBERG \& LEVY, 1995; SILVA \& KATO, 1997; ALBUQUERQUE et al., 2000).

A ocorrência de selamento no solo não depende somente das características do solo, como textura, estrutura ou presença de cobertura vegetal, mas também das características da chuva. Dentre essas, a energia cinética das gotas tem-se tornado, nos últimos anos, a propriedade mais comumente utilizada para caracterizar o efeito da chuva no selamento do solo. Experimentalmente, verifica-se que o aumento da energia cinética resulta em redução progressiva da condutividade hidráulica, na condição correspondente à saturação da camada superficial do solo (EDWARDS \& LARSON, 1969; SILVA \& KATO, 1997; AMORIM et al., 2001).

A redução da condutividade hidráulica e da taxa de infiltração leva ao aumento da tensão cisalhante do escoamento superficial, que é função da lâmina de água e da declividade da superfície do solo. À medida que a tensão cisalhante se torna superior à tensão crítica de cisalhamento do solo (força a partir da qual se inicia a erosão), há aumento da perda de solo. 
A tensão crítica para o cisalhamento do solo é dependente das características do solo, como a granulometria, constituição mineralógica e química do solo, estrutura e capacidade de infiltração.

Assim, o objetivo do presente trabalho foi avaliar as perdas de solo e as características da crosta formada em diferentes classes de solos submetidos a diferentes energias cinéticas de chuva simulada.

\section{MATERIAL E MÉTODOS}

Para a avaliação das perdas de solo e do desenvolvimento do selamento, foi realizado experimento no Laboratório de Hidráulica do Departamento de Engenharia Agrícola da UFV, utilizando simulador de chuvas estacionário de bicos múltiplos e oscilantes, construído conforme modelo proposto pelo National Soil Erosion Research Laboratory, vinculado ao Departamento de Agricultura dos Estados Unidos (NSERL/USDA-ARS).

Os tratamentos foram distribuídos conforme delineamento inteiramente casualizado e esquema fatorial 5 x 6, sendo cinco classes de solo (Argissolo Vermelho - PV, Argissolo Vermelho-Amarelo - PVA, Latossolo Vermelho-Amarelo - LVA, Neossolo Flúvico - RUq e Neossolo Quartzarênico - RQo) e seis níveis de energia cinética de impacto direto da gota de chuva $\left(0 ; 525 ; 1.051 ; 2.102 ; 3.153\right.$ e $\left.4.204 \mathrm{~J} \mathrm{~m}^{-2}\right)$, com três repetições, totalizando 90 unidades experimentais.

As classes de solos foram selecionadas devido as suas diferentes características físicas e estruturais, o que permitiu avaliar a influência das mesmas sobre as características da crosta. No que diz respeito à energia cinética, os valores escolhidos foram aqueles inferiores a uma chuvaintensidade de $156 \mathrm{~mm} \mathrm{~h}^{-1}$, duração de uma hora e período de retorno de 500 anos, no município de Viçosa - MG (FREITAS et al., 2001).

Todos os materiais de solo foram secados ao ar e peneirados em malha com abertura de $2 \mathrm{~mm}$. A caracterização dos solos é apresentada na Tabela 1.

TABELA 1. Resultados das análises físicas e carbono orgânico (C.O.) dos solos estudados.

\begin{tabular}{|c|c|c|c|c|c|c|c|}
\hline Solo & Areia Grossa & Areia Fina & Silte & Argila & A.D.A. & G.F. & C.O. \\
\hline & & & $\mathrm{kg}^{-1}$ & & & $\%$ & dag $\mathrm{kg}^{-1}$ \\
\hline RQo & 0,675 & 0,201 & 0,026 & 0,098 & 0,072 & 25,83 & 0,447 \\
\hline RUq & 0,206 & 0,311 & 0,177 & 0,307 & 0,011 & 96,50 & 0,481 \\
\hline PVA & 0,232 & 0,163 & 0,132 & 0,473 & 0,364 & 23,02 & 1,746 \\
\hline PV & 0,202 & 0,164 & 0,144 & 0,490 & 0,308 & 37,10 & 1,334 \\
\hline LVA & 0,141 & 0,083 & 0,081 & 0,694 & 0,331 & 52,29 & 1,746 \\
\hline
\end{tabular}

A.D.A. - argila dispersa em água, G.F. - grau de floculação.

A unidade experimental foi constituída de uma coluna de PVC de $250 \mathrm{~mm}$ de diâmetro, preenchida com material de solo até a altura de $20 \mathrm{~cm}$. O solo foi umedecido por fluxo ascendente para evitar qualquer alteração da superfície do solo.

Todas as unidades experimentais foram submetidas à mesma energia cinética total (4.204 $\mathrm{J} \mathrm{m}^{-2}$ ). A superfície do solo contido em três colunas (repetições), correspondentes a cada um dos tratamentos, ficou exposta ao impacto direto das gotas de chuva até que fosse aplicada a energia cinética de $0 ; 525 ; 1.051 ; 2.102 ; 3.153$ ou $4.204 \mathrm{~J} \mathrm{~m}^{-2}$, conforme o tratamento. Por exemplo, as colunas correspondentes ao tratamento Argissolo Vermelho e energia cinética $525 \mathrm{~J} \mathrm{~m}^{-2}$ ficaram descobertas até que fossem aplicados $525 \mathrm{~J} \mathrm{~m}^{-2}$. A partir desse momento, a superfície do solo foi coberta com manta sintética de alta permeabilidade (Bidim) com a finalidade de proteger o solo e cessar o desenvolvimento do selamento. As colunas permaneceram cobertas até que fosse aplicado o total de $4.204 \mathrm{~J} \mathrm{~m}^{-2}$. Dessa forma, as colunas em que foi aplicada a energia cinética de $0 \mathrm{~J} \mathrm{~m}^{-2}$, permaneceram cobertas durante todo o teste, e aquelas em que foi aplicada a 
energia cinética de $4.204 \mathrm{~J} \mathrm{~m}^{-2}$, ficaram permanentemente expostas ao impacto direto da chuva simulada.

Para fins de determinação das perdas de solo na coluna, o escoamento superficial foi coletado em um reservatório, no qual foi instalado um equipamento denominado Thalimedes, que permitia a medição da variação da altura do nível da água.

As perdas de solo foram determinadas por meio da coleta do solo transportado por arraste superficial para o reservatório de armazenamento do escoamento superficial. A água armazenada foi homogeneizada e, então, foi retirada uma amostra de $250 \mathrm{~mL}$. Esse volume foi levado à estufa, a $100{ }^{\circ} \mathrm{C}$, até que toda água evaporasse, determinando-se, assim, o peso do solo perdido correspondente ao volume de $250 \mathrm{~mL}$ de escoamento superficial. Conhecendo-se o volume total de escoamento superficial, obtido com base nas leituras do Thalimedes e na área do reservatório de armazenamento, foi possível determinar o peso total de solo perdido por teste.

Para a avaliação do desenvolvimento do selamento superficial, antes da realização dos testes, foram enterrados verticalmente, nas colunas de solo, três cilindros de metal de aproximadamente $58 \mathrm{~mm}$ de diâmetro e $50 \mathrm{~mm}$ de altura, sendo um deles destinado à análise micromorfológica, realizada segundo princípios descritos por MURPHY (1986) e modificados por SCHAEFER (1994), outro destinado à análise da macroporosidade (EMBRAPA, 1997) e o último reservado para substituição em eventuais perdas.

Ao final de cada teste, as amostras indeformadas de solo contidas nos anéis metálicos destinadas à análise micromorfológica foram secas em estufa a $45^{\circ} \mathrm{C}$ e, posteriormente, impregnadas com resina de poliéster. Dos blocos resultantes da impregnação com a resina, foram confeccionadas lâminas de vidro da camada superficial do solo. Essa etapa foi realizada no Centro de Desenvolvimento de Tecnologia Nuclear da Universidade Federal de Minas Gerais (CDTN/UFMG).

As lâminas foram levadas para o microscópio biológico AX70 da Olympus Inc. que, por meio de câmera de vídeo ligada a um microcomputador, permitia a obtenção de imagens usando o programa computacional Photoshop 6.0. As imagens foram manipuladas usando os programas computacionais Visual Stitcher Beta para a determinação da espessura da crosta.

Os valores médios de perda de solo para cada classe de solo foram comparados por meio de teste de agrupamento de Scott-Knott, a 5\% de significância, uma vez verificada a homocedasticidade dessa pelo teste de Cochran.

Foram realizadas análises de regressão, utilizando-se do programa estatístico STATISTICA 6.0 (STATISTIC, 2001), com o objetivo de determinar equações ajustadas aos dados obtidos para cada solo, tendo como variáveis dependentes a perda de solo e a espessura da crosta, e como variável independente a energia cinética da chuva.

\section{RESULTADOS E DISCUSSÃO}

Na Tabela 2, são apresentados os valores médios de perda de solo para as diferentes classes de solo avaliadas, e na Tabela 3, a análise de variância.

Na Figura 1, são apresentados os gráficos de perda de solo, em função da energia cinética aplicada, e as equações, ajustadas para as diferentes classes de solo.

A perda de solo no RUq foi significativamente superior à encontrada para os demais solos, sendo os valores obtidos para os Argissolos igualmente superiores aos encontrados para o Neossolo Quartzarênico e o Latossolo Vermelho-Amarelo. O RUq também foi o solo em que a taxa de perda de solo por unidade de Ec (coeficiente angular da equação linear) foi maior. Esse solo, por sua idade jovem, é o que possui menor desenvolvimento de estrutura, o que confere menor tensão crítica de cisalhamento ao solo, favorecendo a erosão hídrica. 
TABELA 2. Valores médios de perda de solo considerando a classe de solo.

\begin{tabular}{cccccr}
\hline \multirow{2}{*}{$\begin{array}{c}\text { Variável } \\
\left(\mathrm{J} \mathrm{m}^{-2}\right)\end{array}$} & \multicolumn{5}{c}{ Classes de Solo } \\
\cline { 2 - 6 } & RQo & RUq & $\begin{array}{c}\text { PVA } \\
\text { t ha }^{-1}\end{array}$ & PV & LVA \\
\cline { 2 - 6 } 5 & 0,7 & 2,7 & 0,3 & 0,6 & 2,3 \\
525 & 0,1 & 16,9 & 6,9 & 3,2 & 2,0 \\
1.051 & 4,3 & 19,8 & 20,0 & 21,7 & 10,2 \\
2.102 & 14,5 & 41,9 & 29,8 & 29,1 & 20,2 \\
3.153 & 11,2 & 53,7 & 51,6 & 54,3 & 13,9 \\
4.204 & 21,2 & 80,9 & 55,1 & 42,5 & 32,3 \\
\hline Média $^{1}$ & $8,7 \mathrm{C}$ & $36,0 \mathrm{~A}$ & $27,3 \mathrm{~B}$ & $25,3 \mathrm{~B}$ & $13,5 \mathrm{C}$ \\
\hline
\end{tabular}

${ }^{1}$ Letras diferentes entre solos que apresentam homogeneidade de variância, indicam diferenças significativas, pelo teste de agrupamento de Scott-Knott, a 5\% de significância.

TABELA 3. Análise de variância da perda de solo considerando a energia cinética e a classe de solo.

\begin{tabular}{ccc}
\hline Fonte de Variação & GL & Quadrado Médio \\
\hline Solo & 4 & $2.115,058^{* *}$ \\
Ec d/RQo & 5 & $196,941^{*}$ \\
Ec d/RUq & 5 & $2.459,964 * *$ \\
Ec d/PVA & 5 & $1.543,818^{* *}$ \\
Ec d/PV & 5 & $1.353,893^{* *}$ \\
Ec d/LVA & 5 & $401,345^{*}$ \\
Resíduo & 59 & 67,815 \\
\hline C.V. (\%) & 36,79 \\
\hline * e** significativos a 5 e 1\% de probabilidade, respectivamente, pelo teste F.
\end{tabular}

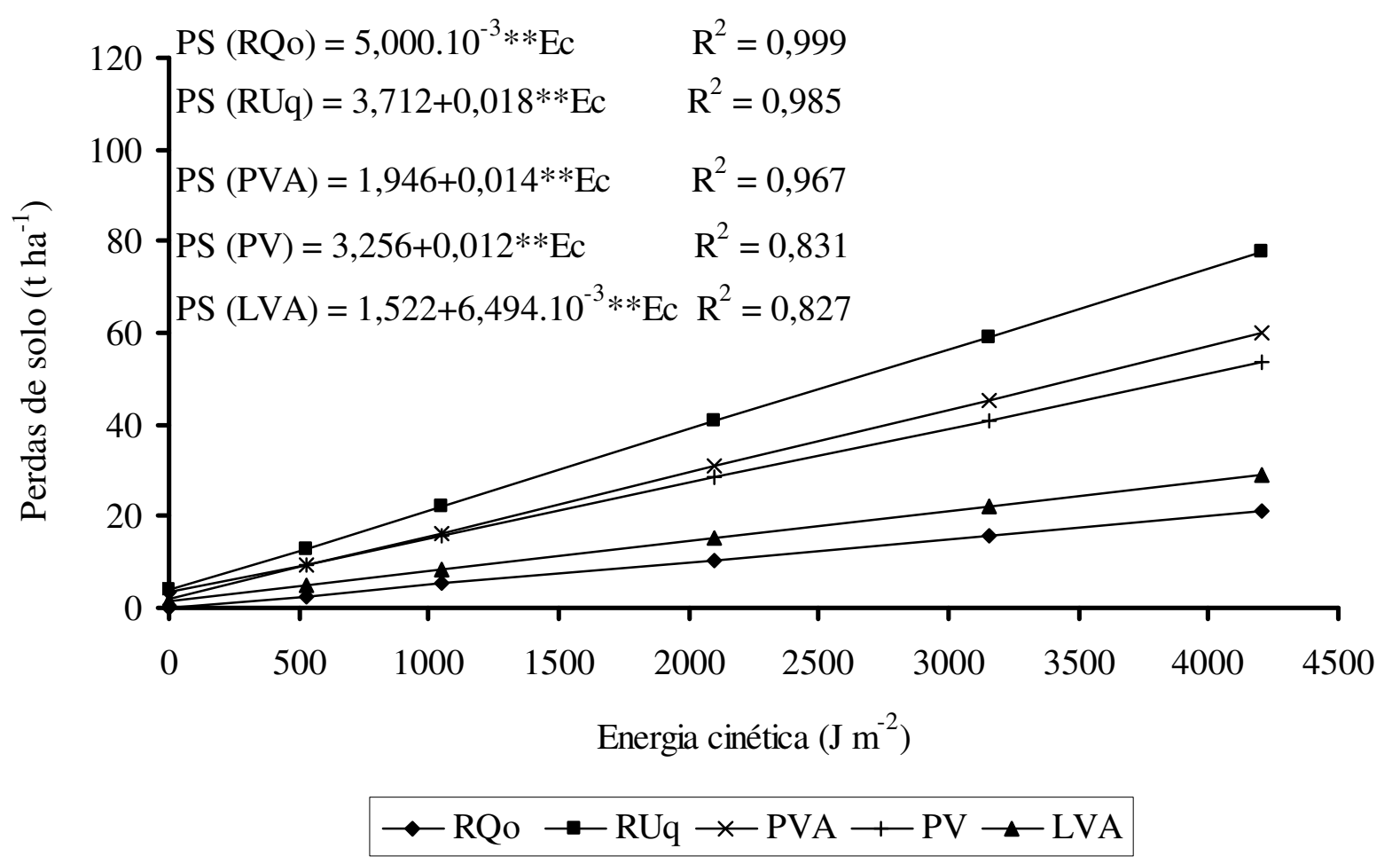

FIGURA 1. Perda de solo (PS) considerando a energia cinética aplicada (Ec) e a classe de solo. **: significativo a $1 \%$, pelo teste $\mathrm{t}$. 
Os resultados evidenciam que o aumento da energia cinética provocou aumento progressivo da perda de solo. A redução da taxa de infiltração provocada pelo desenvolvimento da crosta, provavelmente, fez com que houvesse aumento da tensão cisalhante do escoamento superficial, o que aumentou a sua capacidade de arraste das partículas de solo.

Por outro lado, o RQo e o LVA apresentaram perda de solo significativamente inferior à dos demais solos, uma vez que suas características lhes conferiam maior tensão crítica de cisalhamento. No RQo, além de menor teor de argila, suas partículas constituintes (areia) são mais pesadas, e a tensão cisalhante do escoamento superficial não foi capaz de carrear grande quantidade dessas partículas. O mesmo pode ser dito para o LVA, já que, por apresentar agregados mais estáveis, o impacto das gotas de chuva não foi suficiente para desagregá-los totalmente, nem houve tensão cisalhante do escoamento superficial significativa para carreá-los.

Nas Figuras 2 a 5, são apresentadas algumas das imagens do microperfil utilizadas para a avaliação das características micromorfológicas da crosta decorrente da aplicação de energias cinéticas crescentes, para cada classe de solo, em que se pode observar o selamento em todos os solos.

Nas fotomicrografias dos solos que foram mantidos cobertos durante todo o teste $\left(0 \mathrm{~J} \mathrm{~m}^{-2}\right)$ observa-se a presença de poros largos e interligados ao redor dos grãos simples (RQo) e/ou dos agregados, o que determinou condições favoráveis à infiltração.

Uma parte das fotomicrografias mostra o desenvolvimento de crostas estruturais [Figuras 2(b), 2(c); 3(b), 3(c); 4(b); 5(b)], formadas pelo rearranjo das partículas e microagregados resultantes do distúrbio estrutural provocado pelo impacto das gotas de chuva. Esse tipo de crosta apareceu principalmente quando foram aplicados menores níveis de energia cinética. No entanto, crostas erosionais apareceram com a aplicação dos maiores níveis de energia cinética [Figuras 2(d), 2(e); 3(d), 3(e), 4(c), 4(d), 4(e), 5(c), 5(d) e 5(e)].

No RQo (Figura 2), foi possível observar maior concentração de grãos de areia fina na superfície do solo e iluviação de partículas finas a poucos milímetros abaixo da superfície do solo.

Nas fotomicrografias obtidas para o RUq (Figura 3), observou-se a quebra dos agregados da superfície e iluviação das partículas resultantes no microperfil, havendo o preenchimento dos vazios e, conseqüentemente, acentuada redução da macroporosidade. Além disso, evidenciou-se expressivo surgimento de poros planares. Esses poros, que surgem paralelos à superfície, são pouco interconectados e exercem pequena influência na condutividade hidráulica do solo.

No PVA (Figura 4), evidenciou-se forte empacotamento dos agregados localizados na superfície, que fizeram com que os vazios, antes largos e comunicantes, se tornassem descontínuos, sendo observadas numerosas microfissuras não-comunicantes. $\mathrm{O}$ mesmo foi observado no Argissolo Vermelho.

No LVA (Figura 5), observa-se certo grau de empacotamento e destruição dos agregados da superfície, que promoveram redução da macroporosidade da camada superficial, que não foi tão drástica quanto aquela observada para o RUq, PVA e PV. Esse comportamento pode ser explicado pela maior estabilidade dos agregados encontrados naquela classe de solo.

Na Figura 6, são apresentados os gráficos e as equações ajustadas relacionando a espessura da crosta com a energia cinética aplicada, para as cinco classes de solo analisadas.

Observa-se, na Figura 6, que as maiores espessuras da crosta foram observadas para o RQo, e as menores, para o RUq. Como o RQo é constituído essencialmente por grãos simples, a energia cinética de impacto direto da gota da chuva promoveu perturbação e acomodação dessas partículas em uma estrutura relativamente mais espessa.

Nos demais solos, parte da energia cinética de impacto direto da gota foi utilizada para quebrar e deformar os agregados da superfície, e somente o restante dessa energia foi utilizada na acomodação dos agregados e partículas simples. Assim, a estrutura formada pela reorganização das partículas de solo tornou-se menos espessa do que aquela formada pela reorganização das partículas de areia, tal como aconteceu com o RQo. 
O aumento da energia cinética levou à formação e ao aumento da espessura da crosta que, após atingir valor máximo, apresentou decréscimo em decorrência do desgaste da crosta, provocado, provavelmente, pelo aumento da tensão cisalhante do escoamento superficial.

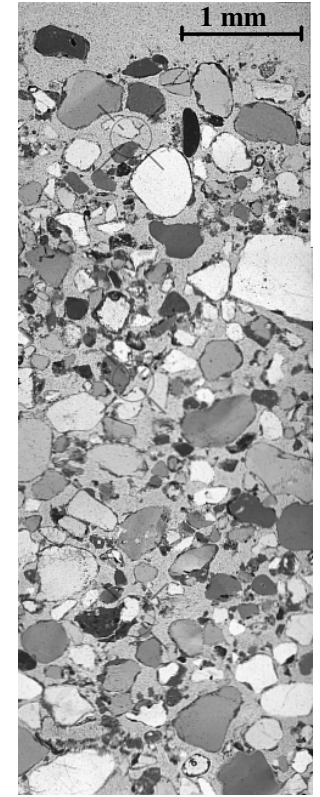

(a)

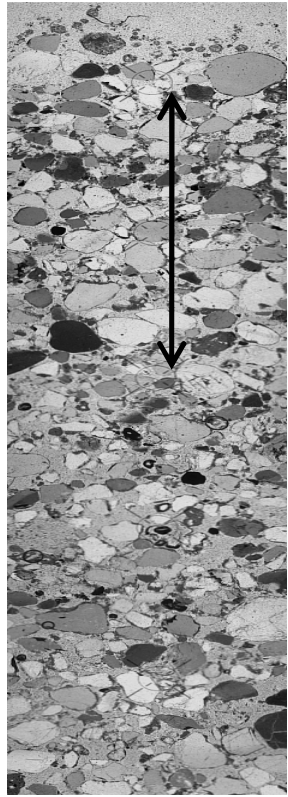

(b)

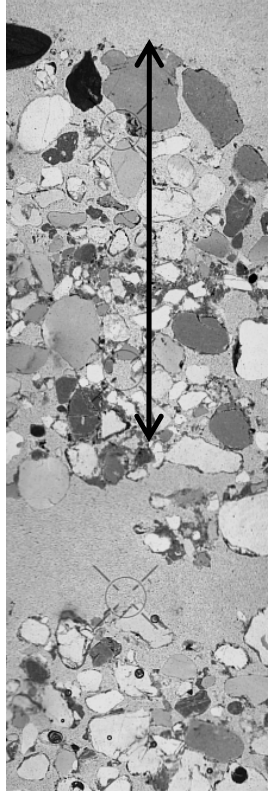

(c)

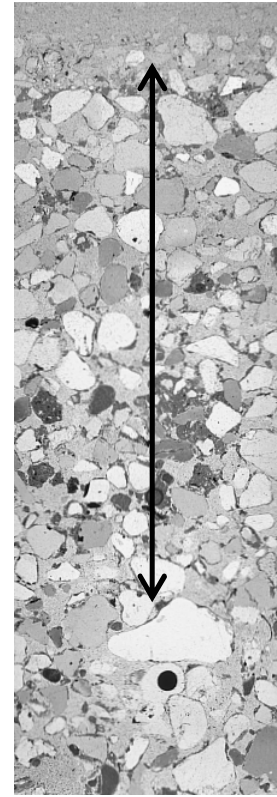

(d)

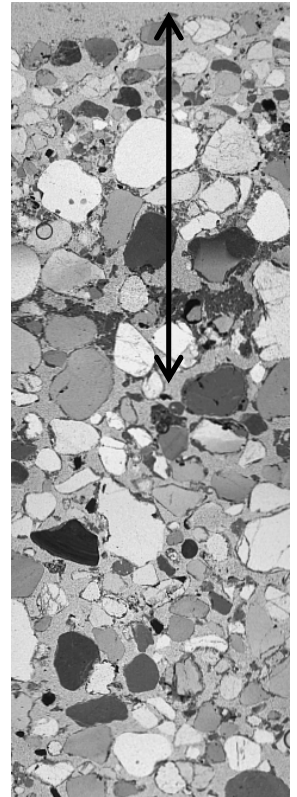

(e)

FIGURA 2. Fotomicrografias da superfície do Neossolo Quartzarênico (RQo) submetido a energias cinéticas crescentes: 0 (a); 525 (b); 1.051 (c); 3.153 (d); e $4.204 \mathrm{~J} \mathrm{~m}^{-2}$ (e). As setas indicam a espessura da crosta.

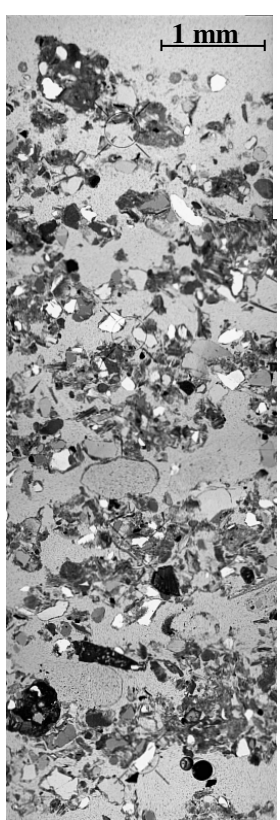

(a)

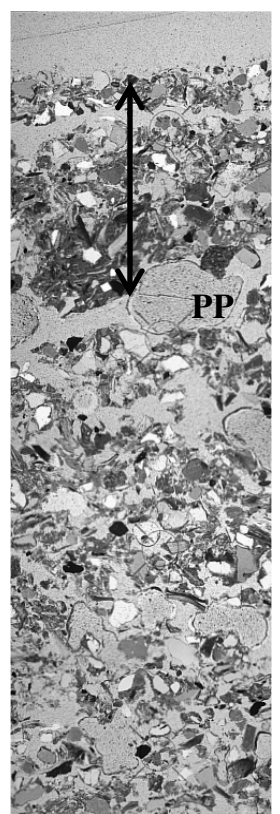

(b)

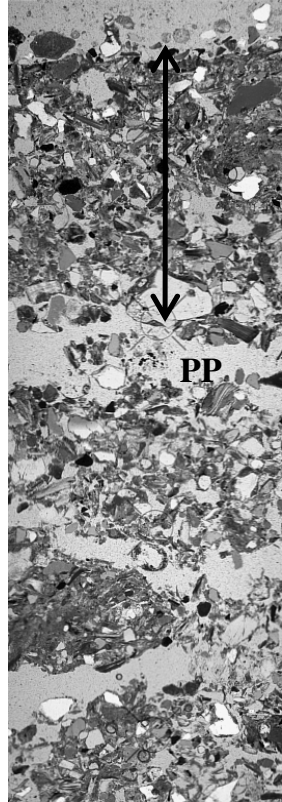

(c)

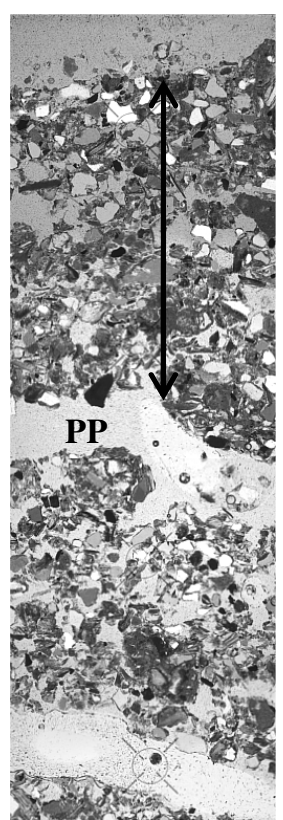

(d)

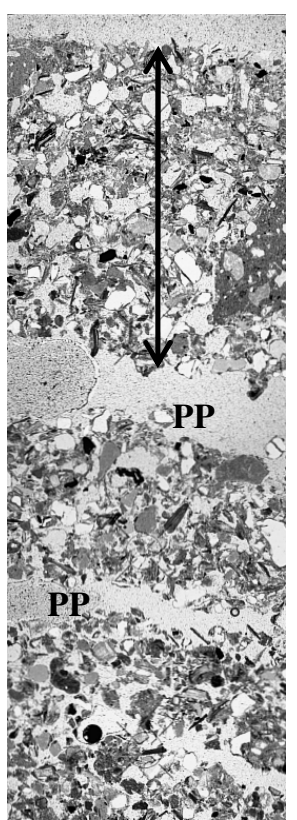

(e)

FIGURA 3. Fotomicrografias da superfície do Neossolo Flúvico (RUq) submetido a energias cinéticas crescentes: 0 (a); 525 (b); 1.051 (c); 2.102 (d); e $4.204 \mathrm{~J} \mathrm{~m}^{-2}$ (e). As setas indicam a espessura da crosta, e PP, os poros planares. 


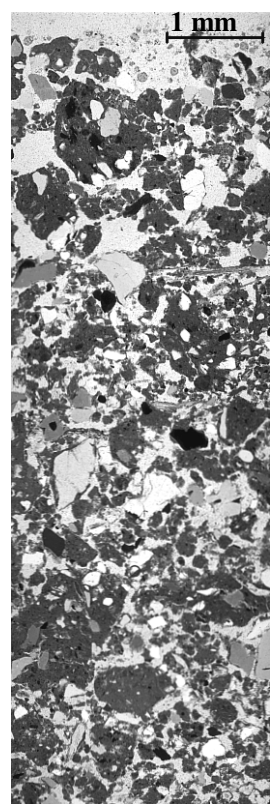

(a)

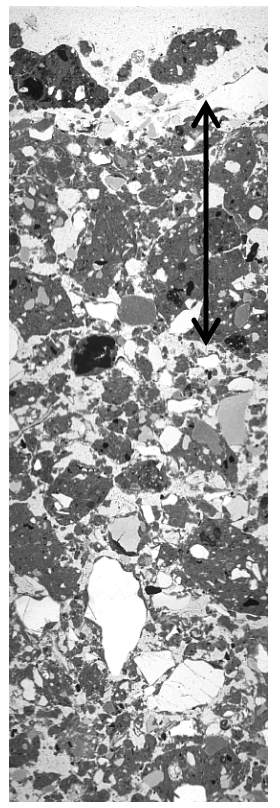

(b)

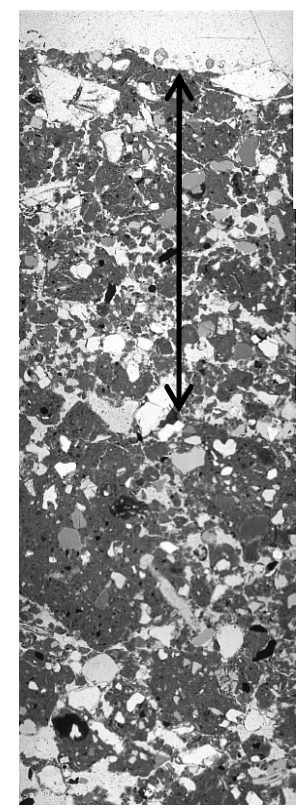

(c)

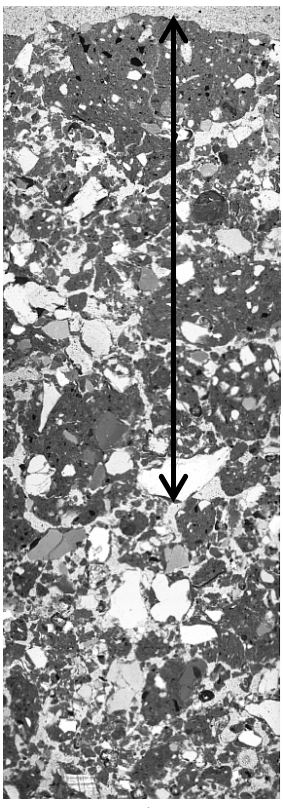

(d)

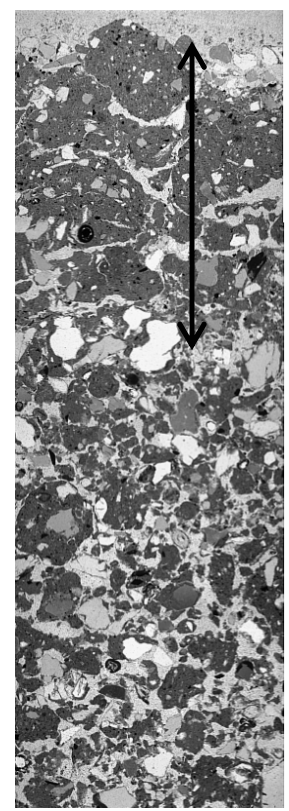

(e)

FIGURA 4. Fotomicrografias da superfície do Argissolo Vermelho-Amarelo (PVA) submetido a energias cinéticas crescentes: 0 (a); 525 (b); 1.051 (c); 3.153 (d); e $4.204 \mathrm{~J} \mathrm{~m}^{-2}$ (e). As setas indicam a espessura da crosta.

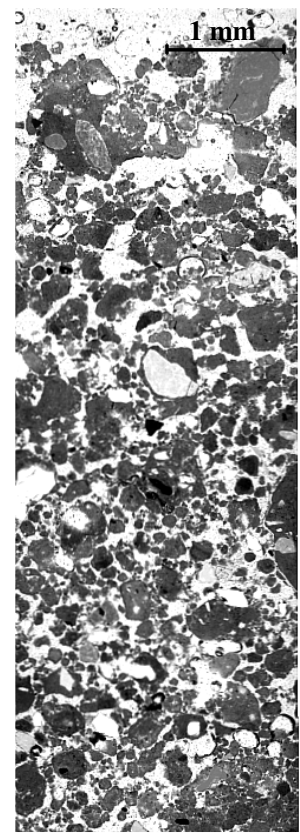

(a)

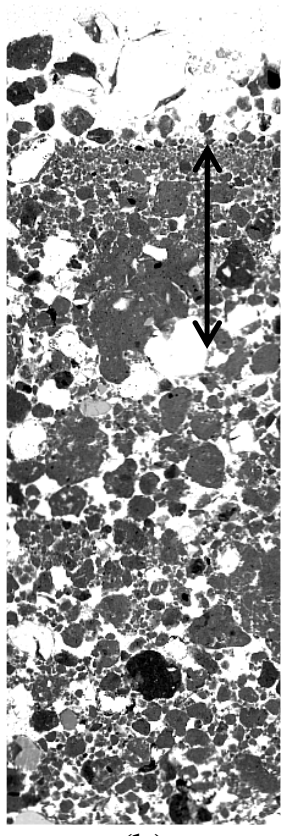

(b)

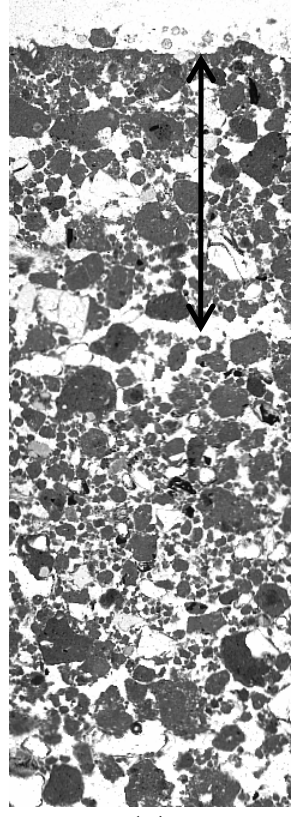

(c)

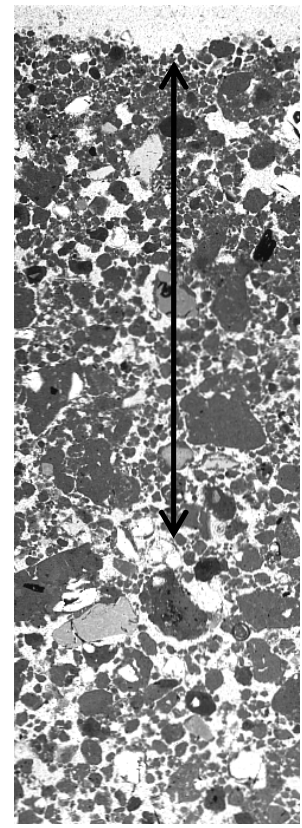

(d)

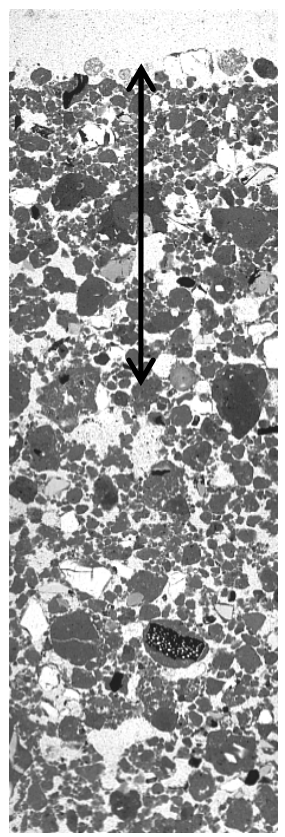

(e)

FIGURA 5. Fotomicrografias da superfície do Latossolo Vermelho-Amarelo (LVA) submetido a energias cinéticas crescentes: 0 (a); 525 (b); 1.051 (c); 3.153 (d); e $4.204 \mathrm{~J} \mathrm{~m}^{-2}$ (e). As setas indicam a espessura da crosta. 


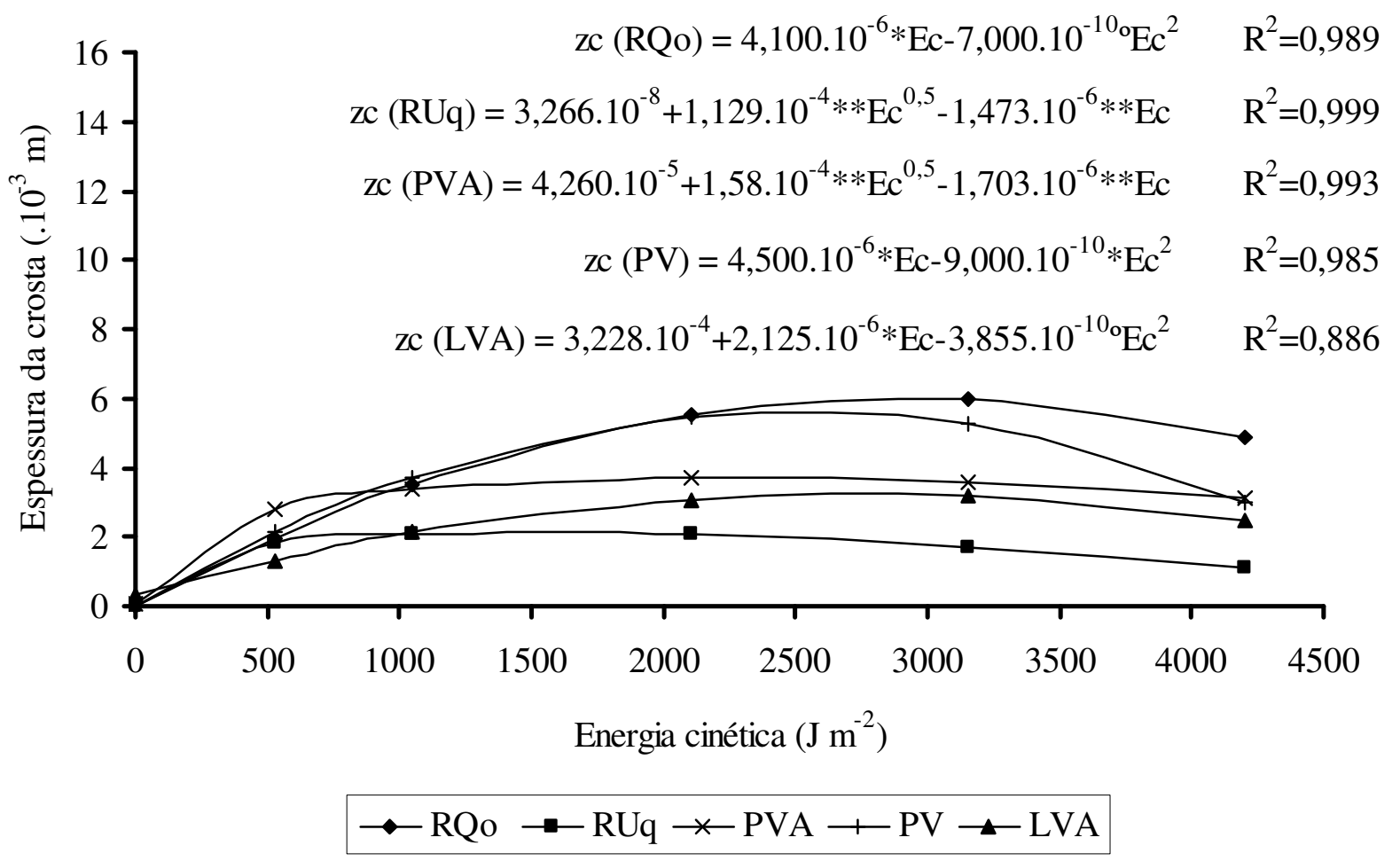

FIGURA 6. Espessura da crosta (zc) considerando a energia cinética aplicada (Ec) e a classe de solo. ${ }^{* *}, * \mathrm{e}^{\circ}$ : significativo a $1 ; 5$ e $10 \%$, respectivamente, pelo teste $\mathrm{t}$.

\section{CONCLUSÕES}

Todas as classes de solo avaliadas evidenciam o desenvolvimento de crosta quando são aplicados valores crescentes de energia cinética da chuva.

O aumento progressivo das perdas de solo é conseqüência do aumento da tensão cisalhante do escoamento superficial provocado, provavelmente, pela redução da infiltração devido ao desenvolvimento do selamento.

Solos arenosos ou argilosos, com estrutura microgranular, apresentam menores perdas de solo em decorrência das suas maiores tensões cisalhantes críticas.

As características da crosta apresentam variação temporal dependente da energia cinética da chuva e da tensão cisalhante do escoamento superficial, que, por sua vez, levam à formação de crostas estruturais e erosionais.

\section{REFERÊNCIAS}

ALBUQUERQUE, J.A.; CASSOL, E.A.; REINERT, D.J. Relação entre a erodibilidade em entressulcos e estabilidade dos agregados. Revista Brasileira de Ciência do Solo, Viçosa, v.24, n.1, p.141-51, 2000.

AMORIM, R.S.S.; SILVA, D.D.; PRUSKI, F.F.; MATOS, A.T. Influência da declividade do solo e da energia cinética de chuvas simuladas no processo de erosão entre sulcos. Revista Brasileira de Engenharia Agrícola e Ambiental, Campina Grande, v.5, n.1, p.124-30, 2001.

BERTOL, I.; COGO, N.P.; LEVIEN, R. Cobertura morta e métodos de preparo do solo na erosão hídrica em solo com crosta superficial. Revista Brasileira de Ciência do Solo, Campinas, v.13, n.3, p.373-9, 1989.

CHEN, Y.; TARCHITZKY, J.; BROUWER, J.; MORIN, J.; BANIN, A. Scanning electron observations on soil crusts and their formation. Soil Science, Baltimore, v.12, n.1, p.49-55, 1980. 
EDWARDS, W.M.; LARSON, W.E. Infiltration of water into soils as influenced by surface seal development. Transactions of the ASAE, St. Joseph, v.12, n.4, p.463-65,70, 1969.

EMBRAPA. EMPRESA BRASILEIRA DE PESQUISA AGROPECUÁRIA. Manual de métodos de análise de solo. 2.ed. Rio de Janeiro, 1997. 212 p.

FARIA, J.C.; SCHAEFER, C.E.G.R.; RUIZ, H.A.; COSTA, L.M. Effects of weed control on physical and micropedological properties of brazilian ultisol. Revista Brasileira de Ciência do Solo, Viçosa, v.22, p.731-41, 1998.

FREITAS, A.J.; SILVA, D.D.; PRUSKI, F.F.; PINTO, F.A.; PEREIRA, S.B.; GOMES FILHO, R.R.; TEIXEIRA, A.F.; BAENA, L.G.N.; MELLO, L.T.A.; NOVAES, L.F. Equações de chuvas intensas no Estado de Minas Gerais. Belo Horizonte: COPASA, 2001. 65 p.

McINTYRE, D.S. Permeability measurements of soil crusts formed by raindrop impact. Soil Science, Baltimore, v.85, p.185-9, 1958.

MURPHY, C.P. Thin section preparation of soil and sediments. Berkamsted: Academic Publisher, 1986. 149 p.

SCHAEFER, C.E.G.R. Soils and paleosols from northeastern Roraima, north Amazonia:

geomorphology, genesis and landscape evolution. 1994. 353 f. Tese (PhD) - University of Reading, Reading, Berkshire, UK, 1994.

SHAINBERG, I.; LEVY, G.J. Infiltration and seal formation processes. In: AGASSI, M. Soil erosion, conservation, and rehabilitation. New York: Marcel Dekker, 1995. p.1-22.

SILVA, C.L.; KATO, E. Efeito do selamento superficial na condutividade hidráulica saturada da superfície de um solo sob cerrado. Pesquisa Agropecuária Brasileira, Brasília, p.32, n.2, p.213-20, 1997.

STATISTIC 6.0. Tulsa: 2001.

VALENTIN, C.; BRESSON, L.M. Morphology, genesis and classification of surface crusts in loamy and sandy soils. Geoderma, Amsterdam, v.55, p.225-45, 1992. 